\title{
Disseminated lichen sclerosus in a child: a case report ${ }^{\star}$
}

\author{
Camila Freitas Lobo Novis ${ }^{1}$ \\ Lourenço de Azevedo Lima ${ }^{1}$ \\ Antonio Macedo D'Acri ${ }^{1}$
}

\author{
Natacha de Carvalho Mello Haddad ${ }^{1}$ \\ Ricardo Barbosa Lima ${ }^{1}$ \\ Osvania Maris Nogueira ${ }^{1}$
}

Lichen sclerosus (LS) is a benign, chronic, inflammatory dermatosis that mainly affects the genitalia and is characterized by pearly-white papules..$^{1-3}$ Its etiology is still unknown; however, genetic factors and autoimmunity have been implicated..$^{1-3}$ It may occur in all age groups and is more prevalent in females than males, with a ratio of $10: 1{ }^{1,4}$ LS shows bimodal distribution with a peak incidence in prepubertal girls and postmenopausal women. ${ }^{3}$ It preferably affects the genital area and extra-genital lesions are rare, especially in children. ${ }^{1}$ This report describes the case of a female child with an exuberant clinical presentation of LS with genital and disseminated extragenital lesions.
A 11-year-old, white, female patient had a 3year history of hypochromic pruritic lesions in the genital area and disseminated hypochromic lesions on the face, trunk, and limbs. Dermatological examination revealed numerous pearly-white papules, some with atrophy, distributed in the frontal region, trunk and limbs, predominating on the dorsal surface of the hands and feet (Figure 1A-C). In some areas, they formed plaques and linear lesions, showing the Koebner phenomenon (Figure 1D). In the genital area, we observed papules and a hypochromic plaque on the labia majora, and erosion and hypochromia on the labia minora and perineum (Figure 2).
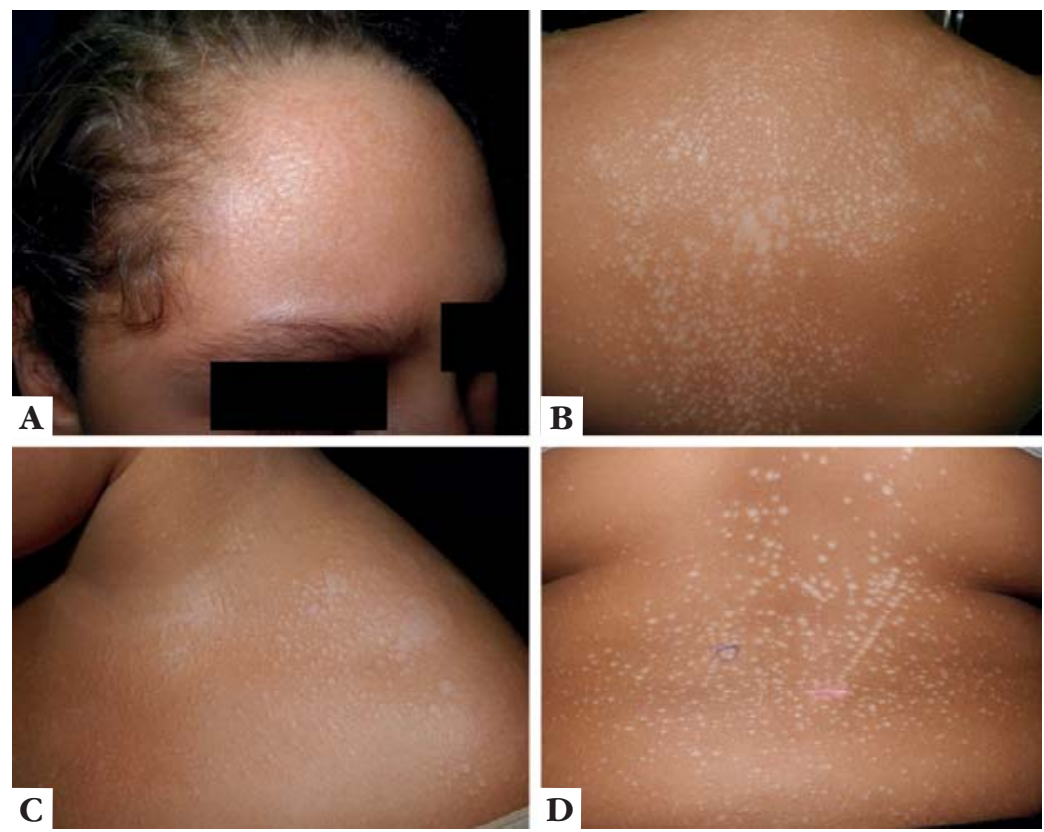

Figure 1: A - Multiple pearly-white papules on the forehead.

B - Multiple lesions on the back. C Pearly-white papules and plaques with a parchment-like aspect in the acromial region. D - Linear lesions showing the Koebner phenomenon on the lower back

Work submitted on 07.07.2014

Approved by the Advisory Board and accepted for publication on 09.09.2014.

Study conducted at the Dermatology Service of the University Hospital Gaffrée e Guinle, Universidade Federal do Estado do Rio de Janeiro (HUGG-UNIRIO) - Rio de Janeiro (RJ), Brazil.

Conflict of interest: None

Financial funding: None

Universidade Federal do Estado do Rio de Janeiro (UNIRIO) - Rio de Janeiro (RJ), Brazil. 


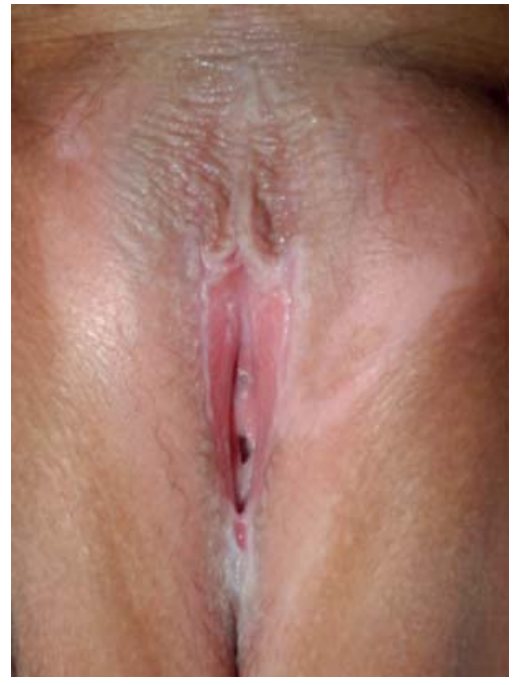

FIGURE 2:

Papules and hypochromic plaque on the left labia majora, and erosion and hypochromia on the labia minora and perineum

Biopsies of the lesions on the trunk, back of the hand and genital area were obtained. Histopathological examination of the genital lesion showed hyperkeratosis, basal layer rectification, in the epidermis, and a band-like mononuclear infiltrate as well as an area of edema and sclerosis, in the dermis, which are features compatible with LS (Figure 3). According to these findings we concluded that it was a case of disseminated LS. Treatment was started with clobetasol propionate $0.05 \%$ ointment, applied to the genital area and most affected regions. The itching in genital lesions improved with treatment. In the other regions, the improvement was not pronounced. The proposed treatment was phototherapy with narrowband UVB, but the patient did not follow the treatment plan.

Approximately $5-15 \%$ of LS cases occur in children. ${ }^{1}$ In children, LS almost always affects the genital area. Only $6 \%$ of patients have extra-genital manifestations of LS. ${ }^{1}$ The patient in the case reported here belongs to this small group of pediatric patients with extra-genital lesions that may mimic other dermato-

\section{REFERENCES}

1. Smith SD, Fischer G. Paediatric vulval lichen sclerosus. Australas J Dermatol. 2009;50:243-8.

2. Fistarol SK, Itin PH. Diagnosis and treatment of lichen sclerosus: an update. Am J Clin Dermatol. 2013;14:27-47.

3. Murphy R. Lichen sclerosus. Dermatol Clin. 2010;28:707-15.

4. Coelho WS, Diniz LM, Souza Filho JB. Lichen sclerosus et atrophicus - report of two cases with atypical presentations. An Bras Dermatol. 2006;81:S297-300.

5. Kreuter A, Wischnewski J, Terras S, Altmeyer P, Stücker M, Gambichler T. Coexistence of lichen sclerosus and morphea: a retrospective analysis of 472 patients with localized scleroderma from a German tertiary referral center. J Am Acad Dermatol. 2012;67:1157-62.

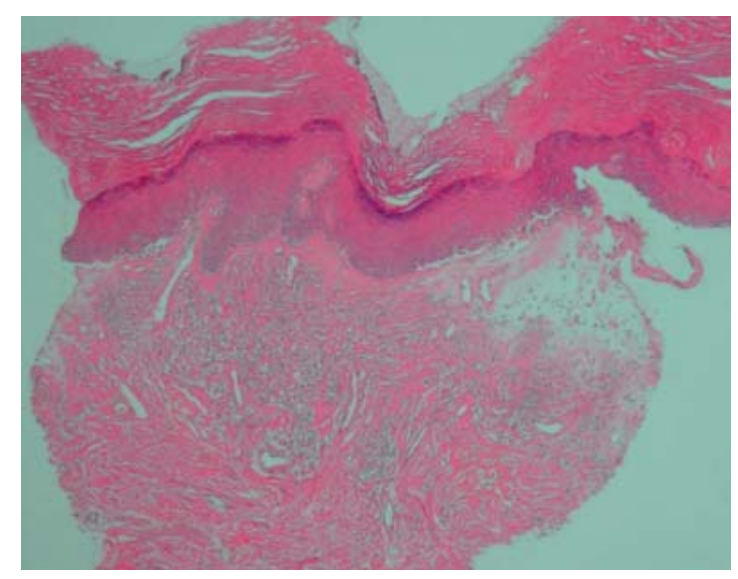

FIGURE 3: Histopathological examination of the genital area revealed hyperkeratosis and basal layer rectification in the epidermis, and a band-like mononuclear infiltrate as well as an area of edema and sclerosis in the dermis. (HE, 40x)

ses, which makes diagnosis more difficult. The main differential diagnosis of the genital lesions are vitiligo, lichen simplex chronicus and sexual abuse, whereas the main differential diagnosis of the extra-genital lesions are localized scleroderma, lichen planus, lichen nitidus, vitiligo and psoriasis. About LS's relationship with localized scleroderma, a recent study with 472 patients has indicated that the frequency of LS in patients with localized scleroderma is higher than in the general population, which raises the hypothesis of a common autoimmune pathophysiological mechanism. ${ }^{5}$

In our case, the complaint of itching and the clinical examination of the genital area were fundamental to the clinical diagnosis.

This case report of a child with an exuberant clinical presentation of genital LS with disseminated extra-genital lesions aims to illustrate a rare clinical presentation of LS, in order to support the clinical diagnosis of LS and draw attention to the importance of examining the genital area of these patients.

How to cite this article: Novis CFL, Haddad NCM, Lima LA, Lima RB, D'Acri AM, Nogueira OM. Disseminated lichen sclerosus in a child: a case report. An Bras Dermatol. 2015;90(2):283-4. 